Bull. Chem. Soc. Ethiop. 2021, 35(1), 1-16.

(c) 2021 Chemical Society of Ethiopia and The Authors

ISSN 1011-3924

DOI: https://dx.doi.org/10.4314/bcse.v35i1.1

Printed in Ethiopia

Online ISSN 1726-801X

\title{
SALLE COMBINED WITH LD-DLLME FOR PESTICIDES ANALYSIS IN SUGAR
} AND SOIL SAMPLES

\author{
Teshome Tolcha ${ }^{1}$, Kefyalew Gomoro ${ }^{2}$ and Negussie Megersa ${ }^{2 *}$ \\ ${ }^{1}$ Department of Chemistry, Kotebe Metropolitan University, P. O. Box 31248, Addis \\ Ababa, Ethiopia \\ ${ }^{2}$ Department of Chemistry, Addis Ababa University, P. O. Box 1176, Addis Ababa, \\ Ethiopia
}

(Received July 31, 2019; Revised September 24, 2020; Accepted January 24, 2021)

\begin{abstract}
In this study, a modified salting-out-assisted liquid-liquid extraction (SALLE) combined with low density dispersive liquid-liquid microextraction (LD-DLLME) has been developed for quantitative determination of multiclass pesticide residues (atrazine, diazinon, ametryn, terbutryn, chlorpyrifos, dimethametryn, 4,4'dichlorodiphenyldichloroethylene (4,4'-DDE), 4,4'-dichlorodiphenyldichloroethane (4,4'-DDD) and 4,4'-dichlorodiphenyltrichloroethane $\left(4,4^{\prime}-\mathrm{DDT}\right)$ ) levels in sugar and soil samples coupled with gas chromatography-mass spectrometry (GC-MS) detection. The extract was enriched after combining SALLE to LD-DLLME and enrichment factor obtained ranged 30-121. Under the optimum conditions, the linearity of the method was in the range of 6.25-100 $\mathrm{ng} \mathrm{g}^{-1}$ for atrazine, ametryn, terbutryn, dimethametryn and 4,4'-DDT, and in the range of 2.5$100 \mathrm{ng} \mathrm{g}^{-1}$ for diazinon, chlorpyrifos and 4,4'-DDD, and in the range of 1-100 for 4,4'-DDE with correlation coefficient of 0.992 or better. The limits of detection (LODs) ranged from $0.01-0.25 \mathrm{ng} \mathrm{g}^{-1}$. The precisions as $\%$ RSD, were below $10 \%$ for both matrices. The recoveries obtained from spiked sugar and soil samples at 5 and $50 \mathrm{ng} \mathrm{g}^{-1}$ ranged from 79 to $111 \%$. The method was subsequently applied to real sugar and soil samples. All the pesticides investigated were not detected in the sugar sample. The soil sample was contaminated by atrazine and ametryn at concentration level of 0.3 and $0.2 \mathrm{ng} \mathrm{g}^{-1}$, respectively.
\end{abstract}

KEY WORDS: SALLE, LD-DLLME, Extraction, Pesticide residues, Sugar, Soil

\section{INTRODUCTION}

Pesticides are broadly used in agriculture to combat a variety of pests that could destroy crops, thereby increasing the world food production and improve quality of the food produced $[1,2]$. However, the extensive use of pesticides caused serious effect on the environment and various organisms, even posing a serious threat to public health. The widespread use of pesticides in the environment causes risks to human health such as cancer and disruption of hormonal functions because of their toxic potential, persistence and tendency to bioconcentrate [3]. The concern for health of society has led to strict regulation of maximum residue limit of pesticide residues in food [4]. Therefore, monitoring levels of these pesticides in food and environmental samples is imperative for health risk control and environment protection [5].

Gas chromatography coupled to mass spectrometric (MS) detection is a powerful analytical tool for the analysis of pesticides in various matrices due to its high separation efficiency, low level of detection, enhanced selectivity and identification capabilities. However, a preconcentration step is mandatory prior to measurements due to matrix effect during analysis, strict environmental legislation on pesticide residues and the demand for ultra-trace analysis $[6$, 7].

Despite substantial technological advances in analytical instruments, a sample preparation is usually unavoidable in analysis due to the complexity of some sample matrices, incompatibility of sample medium with the instrument, and the low concentration of the analytes in real samples. Sample preparation is required prior to analysis to clean-up the matrices, isolate and/or concentrate the analytes of interest and rendering them in a form that is compatible with

*Corresponding author. E-mail: negussie.megersa@aau.edu.et; megersane@yahoo.com This work is licensed under the Creative Commons Attribution 4.0 International License 
analytical systems [8]. Thus, different preconcentration methods such as traditional sample preparation techniques like liquid-liquid extraction (LLE) [9], Soxhlet extraction [10] and solidphase extraction (SPE) $[11,12]$ have been widely used for extraction of trace pesticide residues in food matrices. However, these methods are less sensitive, labor intensive, time consuming and require the use of large volumes of potentially toxic organic solvents, which are dangerous for human health and the environment [13]. Therefore, much effort has been made to develop simple, highly sensitive and environmentally friendly, fast and automated sample preparation methods that have a low consumption of samples and could greatly reduce consumption of toxic organic solvents.

Liquid phase microextraction (LPME) is a miniaturized LLE sample preparation approach that uses only a microliter volume of solvent to extract analytes from the samples. It overcomes several disadvantages of LLE as well as some of those of SPME [14]. As a result, green extraction and/or miniaturized methods are appealing in trace analysis [15]. LPME has been extensively explored in various formats including single drop microextraction (SDME) [16], hollow fiber liquid-phase microextraction (HF-LPME) [17] and dispersive liquid-liquid microextraction (DLLME) [18-21]. The volume ratio of the organic solvent to the sample solution in these microextraction techniques is much less, which guarantees high enrichment factors for the extraction [22-24].

Dispersive liquid-liquid microextraction (DLLME) is a microextraction method which was first applied by Rezaee et al. [25]. In this technique, a binary solvent mixture (extraction and disperser solvents) is rapidly injected into the aqueous sample resulting in the formation of cloudy state due to dispersion of the extraction solvent droplets in the sample. The large surface area between the fine droplets and the aqueous phase facilitates the quick transfer of analytes from the sample solution into the extraction phase. Subsequent centrifugation of the mixture causes sedimentation of the fine droplets at the bottom of the conical tube. The sediment phase can be collected using a syringe and analyzed with appropriate analytical instrument. DLLME has become a very popular microextraction method due to its simplicity, rapidity, high enrichment factors, and low organic solvent consumption [26]. It has been widely used for analysis of trace amounts of analytes in environmental, food, and biological samples [27].

Salting-out LLE is another mode of liquid-liquid extraction using acetonitrile, acetone and isopropanol as extractants [28]. It involves addition of electrolytes to the aqueous phase in order to increase distribution ratio of a particular solute. The addition of a salt decreases the interfacial tension between the aqueous phase and the extractant, resulting in sufficient dispersion of extractant micro-droplets into the aqueous phase under the assistance of external shaking which significantly improves the extraction efficiency of analytes $[29,30]$. SALLE was found to be simple, fast, cheap and environmentally friendly extraction technique [31, 32]. Compared with conventional LLE, SALLE is more efficient, can be used for extraction of wide range analytes and greener. It has been successfully applied for pesticides analysis in honey, river water and human urine [8], lake water [31], sea water, wastewater and urine [33] and banana juice [34].

The enrichment factor of SALLE method is very small compared to the solvent based microextraction and thus the purpose of the extraction is mainly to clean-up the matrices. Therefore, there is a demand to couple SALLE techniques with solvent based microextraction so as to enhance the enrichment factor and preconcentrate the trace level pesticide residues prior to instrumental analysis. On the other hand, DLLME is not a convenient sample preparation method for solid samples due to the small volume of extraction solvent used. The combining of several extraction techniques to overcome the deficiencies of each technique, or to obtain the advantages of both, has been applied in some methods to extract pesticides from different samples. Thus, it is necessary to combine DLLME with SALLE method in order to overcome the stated limitations. Therefore, the objective of this study is to couple SALLE with LDDLLME for clean-up and preconcentration of trace level multiclass pesticide residues in sugar and soil matrices. The technique combines superior advantages of SALLE and DLLME. 
Chemicals and reagents

\section{EXPERIMENTAL}

Analytical grade pesticide standards of atrazine, diazinon, ametryn, terbutryn, chlorpyrifos, dimethametryn, 4,4'-DDE, 4,4'-DDD, 4,4'-DDT were purchased from Dr. Ehrenstorfer (Augsburg, Germany). HPLC grade solvents including acetone, methanol and acetonitrile were obtained from Scharlau (Barcelona, Spain), Techno Pharmchem (New Jersey, USA) and SigmaAldrich Chemie GmbH (Buchs, Switzerland), respectively. Ethyl acetate was supplied by VWR BDH Prolabo (West Chester, PA, USA). The extraction solvent used for LD-DLLME was toluene (>99\%) and obtained from Sigma-Aldrich Chemie $\mathrm{GmbH}$ (Buchs, Switzerland). Sodium chloride $(\mathrm{NaCl})$, ammonium sulfate $\left(\left(\mathrm{NH}_{4}\right)_{2} \mathrm{SO}_{4}\right)$ and magnesium sulfate $\left(\mathrm{MgSO}_{4}\right)$ were purchased from BDH Chemicals Ltd (Poole, England). Sodium hydroxide pellet and hydrochloric acid, used to adjust the sample solution $\mathrm{pH}$, were obtained from BDH Laboratory Supplies (Poole, England) and Sigma-Aldrich Chemie GmbH (Steinheim, Germany), respectively. Florisil SPE cartridge and PSA, used for clean-up, were obtained from SigmaAldrich (St. Louis, MO, USA).

\section{Preparation of standard solutions}

Stock standard solutions of $100 \mathrm{mg} \mathrm{L}^{-1}$ each of the pesticides (atrazine, diazinon, ametryn, terbutryn and dimethametryn) were prepared by dissolving $2.5 \mathrm{mg}$ of each standard in methanol in $25 \mathrm{~mL}$ volumetric flask. In the same way, $100 \mathrm{mg} \mathrm{L}^{-1}$ stock standard solutions of chlorpyrifos, 4,4'-DDE, 4,4'-DDD and 4,4'-DDT were prepared in ethyl acetate. An intermediate working solution containing $5 \mathrm{mg} \mathrm{L}^{-1}$ of each analyte was also prepared in the mixture of methanol and ethyl acetate $(50: 50 \mathrm{v} / \mathrm{v})$ for use during optimization of the extraction parameters and stored in a refrigerator at $4{ }^{\circ} \mathrm{C}$ when not used for analysis. A $0.1 \mathrm{M}$ aqueous solution of each of $\mathrm{HCl}$ and $\mathrm{NaOH}$ were prepared and used to adjust the $\mathrm{pH}$ to the required values.

\section{Instruments}

Chromatographic analyses were performed using Agilent Technologies, 7820A gas chromatograph (GC) equipped with Agilent Technologies 5977E inert mass spectrometer (MS) detector and separations were achieved on DB-5MS (USA) ultra-inert capillary column (30 m x $250 \mu \mathrm{m}$ and $0.25 \mu \mathrm{m}$ i.d.). Data acquisition and processing were accomplished with Agilent mass hunter ChemStation software. An electronic balance (Adam Equipment Company, UK) was utilized for weighing during various experiments. The $\mathrm{pH}$ values were measured with Adwa pH meter, model 1020 (Romania) and centrifuge, Model 800 (Beijing, China) was used during sample preparation. Vacuum oven (Labline Instruments, England), ultrasonic heater (Decon F5100b, England), filtrating apparatus with vacuum pump (Quick FIT, England), cellulose acetate filter paper $(0.45 \mu \mathrm{m}$, MicroScience and $110 \mathrm{~mm}$ Smith F1/KA4, Germany) and deionizer (EASY Pure LF, Dubuque) were used in the process of sample preparation and analysis.

\section{Chromatographic conditions}

Chromatographic separation was performed on DB-5MS (USA) ultra-inert capillary column. The mobile phase used was helium gas $(99.999 \%)$ and delivered at a flow rate of $1 \mathrm{~mL} \mathrm{~min}{ }^{-1}$. The GC injection port temperature was maintained at $250{ }^{\circ} \mathrm{C}$. Splitless injection mode was used during the whole analyses. The oven temperature program was set up as follows: $70{ }^{\circ} \mathrm{C}$ for 0 min; increased at $30{ }^{\circ} \mathrm{C} \mathrm{min}{ }^{-1}$ to $150{ }^{\circ} \mathrm{C}$ held for $1 \mathrm{~min}$; then increased at $45{ }^{\circ} \mathrm{C} \mathrm{min}^{-1}$ to $290{ }^{\circ} \mathrm{C}$ for $3 \mathrm{~min}$. In order to confirm the retention times of the analytes, the mass detector was scanned in full mode over the range $m / z 50-550$. Selective ion monitoring (SIM) mode was used by 
selecting the most abundant characteristic ions of each pesticide and two characteristic fragment ions for quantitative determination of all the analytes. The $\mathrm{m} / \mathrm{z}$ selected for SIM mode detection were as follows: atrazine (215.1, 200.1 and 173.1), diazinon (152.1, 137.1 and 124.1), ametryn (228.1, 227.1, 226.1), terbutryn (170.0, 227.1 and 226.1), chlorpyrifos (198.9, 196.9 and 179.1), dimethametryn (213.1, 212.1 and 196.1), 4,4'-DDE (176.1, 246 and 317.9), 4,4'-DDD (165.1, 235 and 237), 4,4'-DDT(199, 235 and 246).

\section{Sampling and sample preparation}

The sugar and soil samples used in this study were collected from Wonji Shoa Sugar Factory and farmlands, Oromia Regional State of Ethiopia, respectively. The geographical location of sampling place is $8^{\circ} 27^{\prime} 14.96^{\prime \prime} \mathrm{N}$ latitude and $39^{\circ} 13^{\prime} 49.41^{\prime \prime} \mathrm{E}$ longitude with elevation of $1552 \mathrm{~m}$ above sea level. A composite of sugar sample (10 portions) was taken from the factory at a time interval of $30 \mathrm{~min}$ randomly. A composite soil sample (10 portions) was also taken from sugarcane farmlands according to the procedure described by Merdassa et al. [13]. Ten holes of $25 \mathrm{~cm}$ depth were made using a spade. Then, $5 \mathrm{~cm}$ thickness slices along the vertical wall of the holes were taken. All sugar and soil samples collected were pooled separately on methanol rinsed aluminum sheet, each having an area of $3 \mathrm{~m}^{2}$ and mixed manually. Both sugar and soil samples were divided into six portions. A small amount was then taken from each portion to make a sub sample of $1 \mathrm{~kg}$ and transported to the laboratory in a chilled insulated box. In the laboratory, the sugar and soil samples were air dried, ground with electric mill, sieved through a $0.25 \mathrm{~mm}$ pore size, wrapped in a methanol rinsed aluminum foil and kept in a polyethylene plastic bag. The resulting samples were stored in a refrigerator at $4{ }^{\circ} \mathrm{C}$ until the time of analysis.

SALLE technique was optimized by using sugar samples as a representative matrix. In order to select the appropriate solvent, a $1 \mathrm{~g}$ of sugar samples was spiked at $50 \mathrm{ng} \mathrm{g}^{-1}$ working standard solution $\left(5 \mathrm{mg} \mathrm{L}^{-1}\right)$ and the solution was homogenized. Then, the content was diluted with $5 \mathrm{~mL}$ deionized water of $\mathrm{pH}$ 7. A $2 \mathrm{~mL}$ extraction solvent was added and allowed to equilibrate for $2 \mathrm{~min}$ and then $25 \%(\mathrm{w} / \mathrm{v}) \mathrm{NaCl}$ was added. The resulting solution was centrifuged at $4000 \mathrm{rpm}$ for $3 \mathrm{~min}$ and the supernatant was carefully withdrawn. After clean-up with florisil SPE cartridge, all extracts obtained from SALLE were further enriched by LDDLLME and each experiment was carried out in triplicate.

\section{SALLE-LD-DLLME procedure}

A $1 \mathrm{~g}$ of each soil or sugar sample was accurately weighed and transferred into centrifuge tube and then subsequently spiked with appropriate concentrations of the target analyte using a mixture of standard solution. A $5 \mathrm{~mL}$ of distilled and deionized water adjusted to $\mathrm{pH} 7$ was added to dissolve the solid samples, to make the sample matrices more accessible to the extraction solvent and to remove water soluble components [35]. Then, $2 \mathrm{~mL}$ acetonitrile was added to the resulting solution and the mixture was shaken in order to homogenize the content. After keeping for 3 min to establish equilibrium, $25 \%$ (w/v) $\mathrm{MgSO}_{4}$ was added to the solution mixture and was shaken until the salt was dissolved. The solution was separated into two clear phases after centrifugation at $3000 \mathrm{rpm}$ for $2 \mathrm{~min}$. The upper solution (acetonitrile extract) of sugar sample was cleaned by packed florisil SPE cartridge, conditioned by $5 \mathrm{~mL}$ acetonitrile and eluted with $2 \mathrm{~mL}$ acetonitrile. The soil sample extract was also diluted by $2 \mathrm{~mL}$ acetonitrile and transferred to the d-SPE tube containing $1.2 \mathrm{mg}$ PSA for clean-up and shaken manually. Then, it was centrifuged for $3 \mathrm{~min}$ at $4000 \mathrm{rpm}$. The collected organic phase extract of both sugar and soil samples were dried in vacuum oven. The residue was dissolved in $0.6 \mathrm{~mL}$ acetone and the resulted solution was subjected to LD-DLLME procedure. A LD-DLLME was adopted from our earlier work [24]. For the DLLME, $5 \mathrm{~mL}$ aqueous solution of $\mathrm{NaCl}, 10 \% \mathrm{w} / \mathrm{v}$, adjusted to $\mathrm{pH} 7$ was placed in home designed modified Pasteur pipettes. The mixture of $50 \mu \mathrm{L}$ toluene and 0.6 $\mathrm{mL}$ acetone containing the pesticide residue (as a disperser solvent) was injected rapidly at room 
temperature using $1 \mathrm{~mL}$ syringe and shaken vigorously. After $10 \mathrm{~min}$, another $0.5 \mathrm{~mL}$ acetone as demulsifier was injected slowly to the resulted solution to break up the emulsion. This was followed by collection of the organic phase using microsyringe and transferred into inserted GC injection vial. Finally, $1 \mu \mathrm{L}$ of the extract was injected directly into the GC-MS system for further instrumental analysis and peak area was used as instrumental response.

\section{RESULTS AND DISCUSSION}

\section{Optimization of SALLE parameters}

The important parameters affecting the extraction efficiency, such as extraction solvent, salt effect, sample $\mathrm{pH}$, and extraction and centrifugation time, were investigated and optimized.

\section{Selection of the type and volume of extraction solvent}

Selection of appropriate extraction solvent is an important step in the optimization for successful application of the SALLE method. The extraction solvent of choice has to meet certain requirements such as high polarity, miscibility with the aqueous phase [34], extraction capability for the analytes of interest, having a density lower than water, ability to form phase separation following the addition of appropriate salt and being environmentally friendly [36]. Based on these requirements acetonitrile, acetone and methanol were tested for extraction efficiency of the target analytes under study. A series of experiments were performed under the same experimental conditions and phase separation of the organic phase and aqueous phase was observed only with acetonitrile. Despite acetonitrile miscibility with water, there is the potential to partition a solution into two layers when salts and/or other organic solvent was added [37]. Therefore, acetone and methanol were ruled out and acetonitrile was selected for further experiments.

To evaluate the effect of acetonitrilevolume, 1.5, 2, 2.5 and $3 \mathrm{~mL}$ were studied. Below 1.5 $\mathrm{mL}$, the layer of the extract formed was not sufficient and it was very difficult to collect the upper organic phase separately. The curve of variation of analytes peak areas versus the volume of acetonitrile as extraction solvent is shown in Figure 1. As the volume of acetonitrile increased, the peak area of most target analytes was slightly increased. From the obtained results, $2 \mathrm{~mL}$ of acetonitrile was chosen as optimum volume for the extraction solvent.

\section{Effect of salt type and amount}

The salting-out effect is commonly used for enhancement of extraction efficiency. Salt addition affects the extraction efficiency in two aspects due to the salting-out effect. It increases the ionic strength which is expected to favor the extraction of the target compounds from the aqueous phase to the organic phase. It also decreases the solubility of the extraction solvent in the aqueous phase while increasing the partitioning into the organic phase [38].

In this study, the effect of three different salts; $\mathrm{NaCl}, \mathrm{MgSO}_{4}$ and $\left(\mathrm{NH}_{4}\right)_{2} \mathrm{SO}_{4}$ was investigated using $25 \%(\mathrm{w} / \mathrm{v})$ of each salt, as apotential salting-out reagent to induce the phase separation of aqueous solution and ACN. It was observed that the smallest peak areas for all of the target analytes were obtained when $\mathrm{NaCl}$ was used. This might be attributed to the reduction in extraction capacity factors resulting from the smaller volume of acetonitrile that may be insufficient to extract the target analyte from the matrix [39]. As shown in Figure 2, the highest peak area was obtained when $\mathrm{MgSO}_{4}$ was used as potential salting-out reagent. This may be due to its high ionic strength per unit concentration in the aqueous phase. It should be noted that any strong Lewis base could have interaction with magnesium and affect the extraction efficiency because magnesium is a strong Lewis acid [40]. Thus, $\mathrm{MgSO}_{4}$ was selected as salting-out reagent for further experiments. 


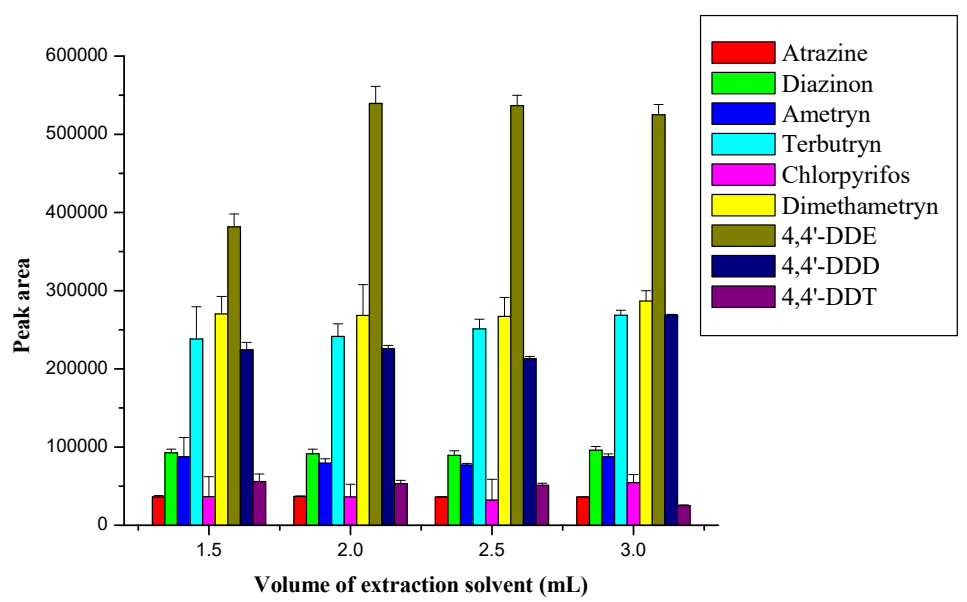

Figure 1. Effect of volume of the extraction solvent. Extraction conditions: $1 \mathrm{~g}$ of sugar spiked at $50 \mathrm{ng} \mathrm{g}^{-1}$ containing the target analytes, extraction solvent; acetonitrile, amount of salt; $25 \%(w / v)$ of $\mathrm{NaCl}$, centrifugation speed; $4000 \mathrm{rpm}$, centrifugation time; $2 \mathrm{~min}$, extraction time; $2 \mathrm{~min}$.

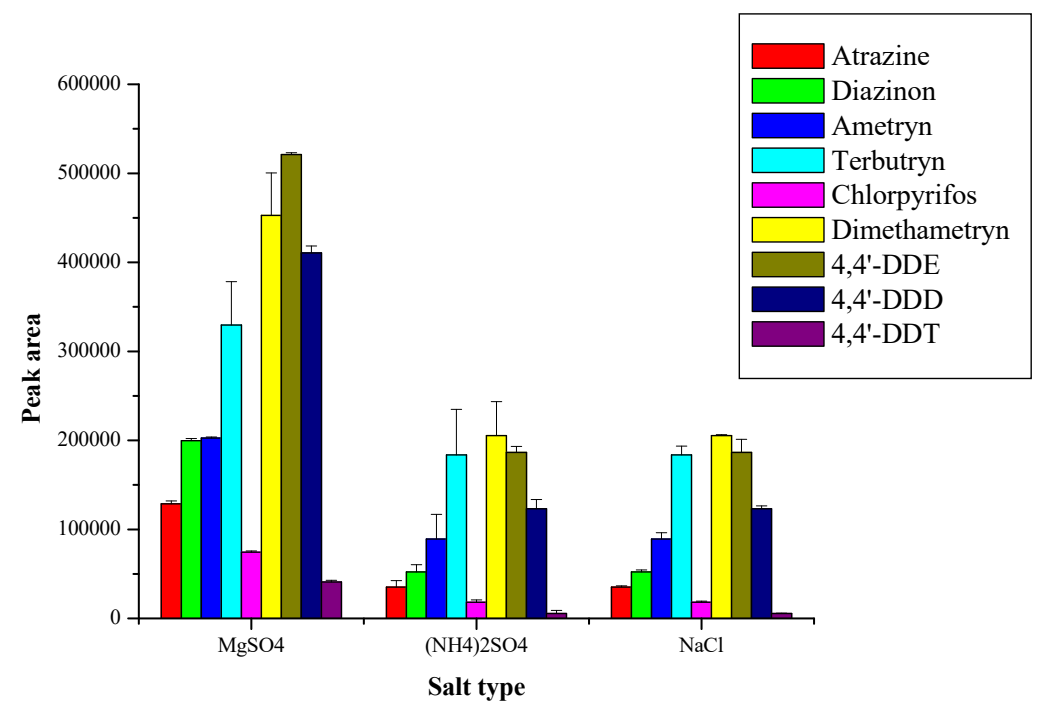

Figure 2. Effect of the salt type. Extraction conditions: $1 \mathrm{~g}$ of sugar spiked at $50 \mathrm{ng} \mathrm{g}^{-1}$ containing the target analytes, extraction solvent; $1.5 \mathrm{~mL}$ acetonitrile, amount of salt; $25 \%(w / v)$, centrifugation speed; $4000 \mathrm{rpm}$, centrifugation time; $2 \mathrm{~min}$, extraction time; $2 \mathrm{~min}$.

Although acetonitrile is miscible with water in any proportion at room temperature, addition of salt significantly reduced the mutual miscibility, even resulting in phase separation of acetonitrile from aqueous phase [24]. The effect of salt was assessed by adding 24-27\% (w/v) of $\mathrm{MgSO}_{4}$. It was observed that $24 \%$ of $\mathrm{MgSO}_{4}$ was not enough to form a phase separation. The 
highest peak area for all target analytes was obtained when $25 \%(\mathrm{w} / \mathrm{v})$ of $\mathrm{MgSO}_{4}$ was used and slightly decreased beyond $25 \%(\mathrm{w} / \mathrm{v})$ of $\mathrm{MgSO}_{4}$ (Figure 3). Therefore, $25 \%$ (w/v) of $\mathrm{MgSO}_{4}$ was selected as the optimum amount of the salt for further experiments.

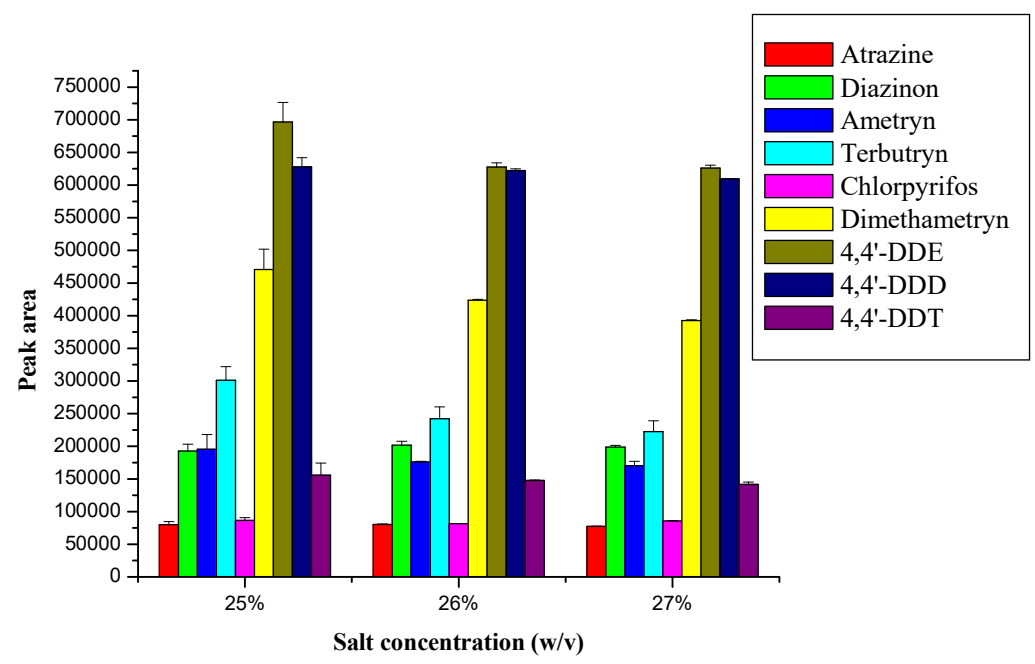

Figure 3. Effect of the amount of salt. Extraction conditions: $1 \mathrm{~g}$ of sugar spiked at $50 \mathrm{ng} \mathrm{g}^{-1}$ containing the target analytes, extraction solvent; $1.5 \mathrm{~mL}$ acetonitrile, salt; $25 \%(w / v)$ $\mathrm{MgSO}_{4}$, centrifugation speed; $4000 \mathrm{rpm}$, centrifugation time; 2 min, extraction time; 2 $\min$.

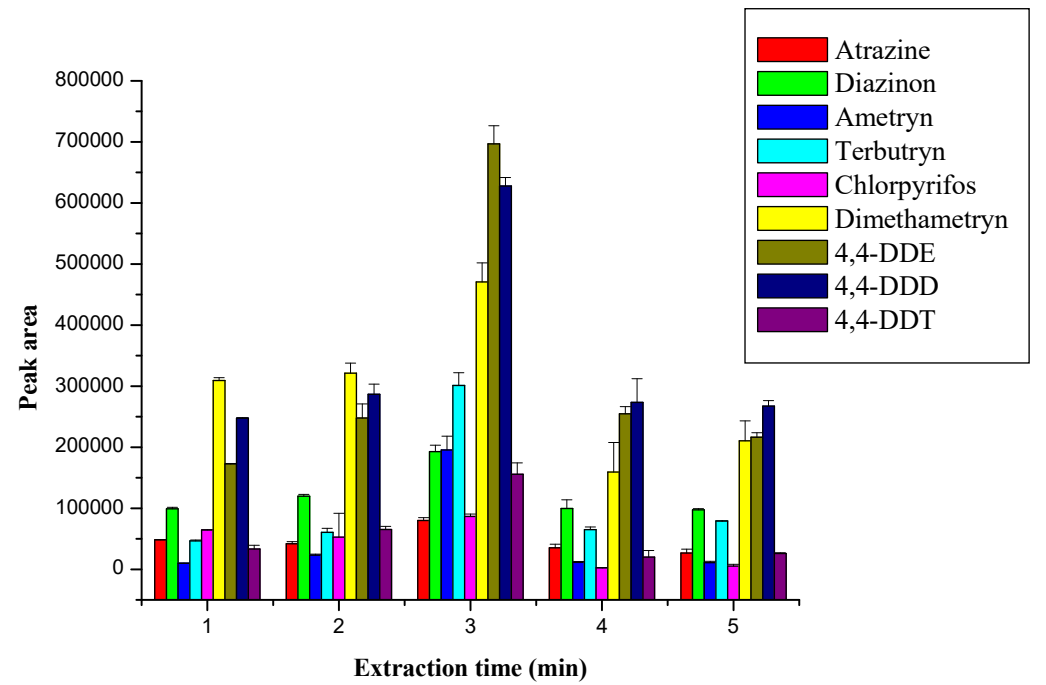

Figure 4. Effect of the extraction time. Extraction condition: $1 \mathrm{~g}$ of sugar spiked at $50 \mathrm{ng} \mathrm{g}^{-1}$ containing the target analytes, extraction solvent; $1.5 \mathrm{~mL}$ acetonitrile, amount of salt; $25 \%(w / v)$ of $\mathrm{MgSO}_{4}$, centrifugation speed; $4000 \mathrm{rpm}$, centrifugation time; 3 min. 


\section{Effect of extraction time}

The extraction time, the time interval from adding the extraction solvent and before starting centrifugation [40], was studied over a range of 1-5 min. Initially extraction efficiency increased as extraction time was increased and peak areas of all of the analytes were enhanced at 3 min (Figure 4). The peak areas of the analytes decrease when extraction time was further increased. This may be due to the fact that long extraction time would result in a decrease of peak areas owing to the dissolution of acetonitrite in water. Hence, extraction time of 3 min was chosen as the optimum extraction time for subsequent experiments.

\section{Effect of $p H$}

The $\mathrm{pH}$ of the sample solution plays important role in the extraction of ionizable and relatively polar compounds since change in solution $\mathrm{pH}$ affects the solubility and stability of the solute due to ionization. This influences the transfer of the analytes from the aqueous phase to the organic phase [41]. The $\mathrm{pH}$ of the solution should be adjusted properly so that additional selectivity can be achieved through adequate control of the $\mathrm{pH}$ [42]. In this study, the effect of the sample solution $\mathrm{pH}$ was investigated by varying from 5 to 9 using diluted $\mathrm{HCl}$ or $\mathrm{NaOH}$ solution. As can be seen in Figure 5, the highest peak areas of the target pesticides were obtained at $\mathrm{pH}$ 7. This may be due to the high stability of the target pesticides in the weakly acidic and weakly alkaline media, and being easily degraded in strongly acidic and alkaline condition [43].Therefore, a sample solution of $\mathrm{pH} 7$ was chosen the optimum extraction condition.

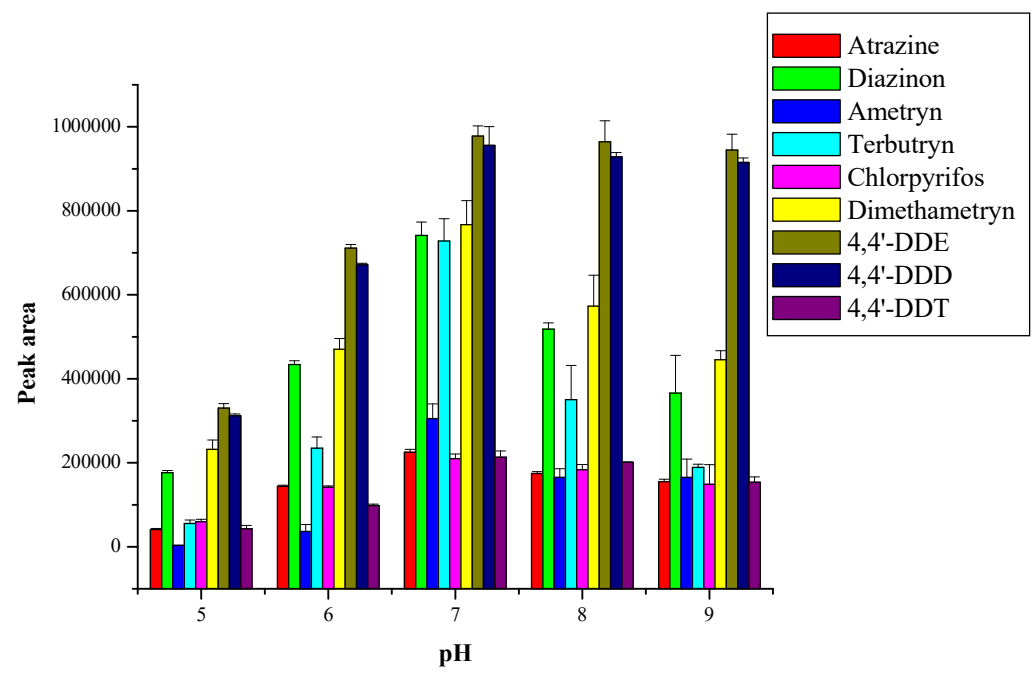

Figure 5. Effect of $\mathrm{pH}$ of the reagent water. Extraction condition: $1 \mathrm{~g}$ of sugar spiked at $50 \mathrm{ng} \mathrm{g}^{-1}$ containing the target analytes, extraction solvent; $1.5 \mathrm{~mL}$ acetonitrile, amount of salt; $25 \%(w / v) \mathrm{MgSO}_{4}$, centrifugation speed; $4000 \mathrm{rpm}$, centrifugation time; $3 \mathrm{~min}$, extraction time; $3 \mathrm{~min}$.

\section{Effect of centrifugation speed and time}

Centrifugation plays a key role in separation of the phases and thus resulting in a clear solution [44]. In order to maximize the response, the effect of centrifugation speed was studied in the 
range of 2000 to $4000 \mathrm{rpm}$. The experimental results revealed that the highest responses of all target analytes were attained at $3000 \mathrm{rpm}$ centrifugation speed. As a result, $3000 \mathrm{rpm}$ was utilized as optimum centrifugation speed for subsequent experiments.

Optimizing the time required for phase separation is also important analytical step in order to obtain a clean extract [31]. To this end, time of centrifugation was varied from 1 to $5 \mathrm{~min}$, at $1 \mathrm{~min}$ interval, keeping the other parameters at the optimum conditions. The experimental result confirmed that centrifugation time of $3 \mathrm{~min}$ to be the optimal and was used in the subsequent experiments.

\section{The enriching efficiency obtained by combining SALLE with LD-DLLME}

The enrichment factor (EF) is defined as the ratio of the final analyte concentration in the organic phase $\left(\mathrm{C}_{\text {org }}\right)$ to the initial concentration of the analyte $\left(\mathrm{C}_{\mathrm{o}}\right)$ in sample solution [3]. In this particular work, EF is the ratio of final analyte peak area in organic phase after SALLE-LDDLLME to the peak area of the analyte in the SALLE extract. To evaluate the enrichment factor, a $1 \mathrm{~g}$ sugar sample spiked at $50 \mathrm{ng} \mathrm{g}^{-1}$ with the target analytes was extracted under the following extraction conditions: $5 \mathrm{~mL}$ deionized water $(\mathrm{pH} 7), 2 \mathrm{~mL}$ acetonitrile, $25 \%$ (w/v) $\mathrm{MgSO}_{4}, 3$ min equilibrium time and centrifuged at $3000 \mathrm{rpm}$ for $3 \mathrm{~min}$. After clean-up, as described in the procedure section, first the acetonitrile extract was analyzed by GC-MS. Then the extraction was repeated, and the supernatant was further enriched by LD-DLLME as described in the procedure section. The peak area of the SALLE acetonitrile extract and that of the SALLE-LD-DLLME was compared as shown in Table 1.

Table 1. The enrichment factor (EF) of the target analytes obtained after combining SALLE with LDDLLME.

\begin{tabular}{|l|c|c|c|}
\hline Analyte & $\begin{array}{c}\text { Peak area obtained } \\
\text { from SALLE }(\mathrm{n}=3)\end{array}$ & $\begin{array}{c}\text { Peak area obtained from } \\
\text { SALLE-LD-DLLME }(\mathrm{n}=3)\end{array}$ & EF \\
\hline Atrazine & 10586 & 407875 & 39 \\
\hline Diazinon & 15955 & 761700 & 48 \\
\hline Ametryn & 20234 & 851049 & 42 \\
\hline Terbutryn & 14487 & 1073093 & 74 \\
\hline Chloropyrifos & 2160 & 260608 & 121 \\
\hline Dimethametryn & 15199 & 260555 & 63 \\
\hline 4,4'-DDE & 19009 & 1202872 & 53 \\
\hline 4,4'-DDD & 23222 & 1228480 & 30 \\
\hline 4,4'-DDT & 11874 & 355754 & 17 \\
\hline
\end{tabular}

\section{Method validation}

The applicability of the proposed method was investigated for determination of presence of the target analyte in terms of linearity, LOD, precision and accuracy. The matrix matched calibration curve was linear over the concentration range from $6.25-100 \mathrm{ng} \mathrm{g}^{-1}$ for atrazine, ametryn, terbutryn, dimethametryn and 4,4'-DDT; $2.50-100 \mathrm{ng} \mathrm{g}^{-1}$ for diazinon, chlorpyrifos and 2,4'-DDD, and 1-100 $\mathrm{ng} \mathrm{g}^{-1}$ for 4,4'-DDE with the coefficients of determination $\left(\mathrm{R}^{2}\right)$ ranging from 0.992 to 0.999 . The LOD was considered as the minimum analyte concentration yielding 3 times the signal-to-noise $(\mathrm{S} / \mathrm{N})$ ratio of the blank and found to be in the range of 0.01 to $0.3 \mathrm{ng} \mathrm{g}$ ${ }^{1}$. Repeatability was studied by extracting and injecting spiked sugar samples at 5 and $50 \mathrm{ng} \mathrm{g}^{-1}$ concentration levels on the same day, under the same experimental conditions. Similarly, reproducibility was evaluated by extracting and injecting the samples spiked at the above two concentration levels in triplicate for three consecutive days. The results, expressed as relative standard deviation (\%RSD) of the peak areas, are shown in Table 2 and acceptable precisions were obtained for all the analytes [34]. 
Table 2. Analytical performance of SALLE-LD-DLLME.

\begin{tabular}{|c|c|c|c|c|c|c|c|c|}
\hline \multirow[t]{2}{*}{ Analyte } & \multirow[t]{2}{*}{$\begin{array}{l}\text { Linear range } \\
\left(\mathrm{ng} \mathrm{g}^{-1}\right)\end{array}$} & \multirow[t]{2}{*}{$\begin{array}{l}\text { LOD } \\
\left(\mathrm{ng} \mathrm{g}^{-1}\right)\end{array}$} & \multirow[t]{2}{*}{ Regression equation } & \multirow[t]{2}{*}{$\mathrm{R}^{2}$} & \multicolumn{2}{|c|}{$\begin{array}{l}\text { Repeatability } \\
(\% \text { RSD }, \mathrm{n}=3)\end{array}$} & \multicolumn{2}{|c|}{$\begin{array}{l}\text { Reproducibility }^{\mathrm{b}} \\
(\% \mathrm{RSD}, \mathrm{n}=3)\end{array}$} \\
\hline & & & & & $5 \mathrm{ng} \mathrm{g}^{-1}$ & $50 \mathrm{ng} \mathrm{g}^{-1}$ & $5 \mathrm{ng} \mathrm{g}^{-1}$ & $50 \mathrm{ng} \mathrm{g}^{-1}$ \\
\hline Atrazine & $6.25-100$ & 0.02 & $Y=20942 x+15652$ & 0.999 & 9.3 & 7.3 & 8.2 & 5.2 \\
\hline Diazinon & $2.50-100$ & 0.08 & $Y=46256 x+4481$ & 0.999 & 4.4 & 3.3 & 8.2 & 3.6 \\
\hline Ametryn & $6.25-100$ & 0.01 & $Y=10349 x+15538$ & 0.995 & 7.9 & 7.2 & 7.0 & 5.1 \\
\hline Terbutryn & $6.25-100$ & 0.03 & $Y=13423 x+2560$ & 0.999 & 8.6 & 4.4 & 9.4 & 1.8 \\
\hline Chlorpyrifos & $2.50-100$ & 0.25 & $Y=14217 x+1796$ & 0.999 & 9.3 & 3.1 & 6.5 & 3.1 \\
\hline Dimethametryn & $6.25-100$ & 0.03 & $Y=10111 x+32706$ & 0.999 & 8.7 & 5.8 & 3.5 & 1.5 \\
\hline 4,4'-DDE & $1.00-100$ & 0.03 & $Y=11748 x+13579$ & 0.997 & 3.0 & 1.7 & 7.8 & 5.0 \\
\hline 4,4'-DDD & $2.50-100$ & 0.06 & $Y=52971 x+22176$ & 0.992 & 2.1 & 1.5 & 0.9 & 0.9 \\
\hline $4,4^{\prime}-\mathrm{DDT}$ & $6.25-100$ & 0.30 & $Y=10863 x+1521$ & 0.998 & 6.0 & 3.9 & 2.1 & 1.9 \\
\hline
\end{tabular}

${ }^{a}$ Studied by extracting and injecting spiked sugar samples on the same day, under the same experimental conditions. ${ }^{b}$ Evaluated by extracting and injecting the samples spiked at the indicated concentration levels in triplicate for three consecutive days.

Recoveries were calculated by comparing the average peak area for the analytes in blank sugar and soil samples spiked before application of the SALLE-LD-DLLME procedure with the peak area of the corresponding sample spiked after application of the SALLE-LD-DLLME procedures. To investigate the accuracy of the proposed method, both sugar and soil samples were spiked at two concentration levels, 5 and $50 \mathrm{ng} \mathrm{g}^{-1}$, and extracted under the optimized conditions in triplicate. Recoveries and the RSD of each target analyte in the sugar and soil samples are shown in Table 3. The recoveries of the real samples at the two spiking levels were in the range $79-111 \%$ and $87-104 \%$, respectively. Therefore, the results obtained revealed that the proposed method is acceptable, and also in agreement with the current EU legislation [32]. Both sugar and soil samples were subjected to the SALLE-LD-DLLME procedure and then the extracts were injected into GC-MS system for analysis. The blank samples were analyzed, but none of these target analytes were detected in the sugar samples while atrazine and ametryn were quantitatively detected at concentration levels of 0.3 and $0.2 \mathrm{ng} \mathrm{g}^{-1}$, respectively, in the soil samples. Typical chromatograms of the unspiked sugar and soil samples, and spiked soil samples with all target analytes are shown in Figure 6.

Table 3. Recoveries and RSD of spiked sugar and soil samples.

\begin{tabular}{|c|c|c|c|c|c|c|c|}
\hline \multirow[t]{2}{*}{ Analyte } & \multirow[t]{2}{*}{ Spiked level (ng g $\left.{ }^{-1}\right)$} & \multicolumn{2}{|c|}{ Sugar } & \multicolumn{2}{|c|}{ Soil } & \multicolumn{2}{|c|}{ Amount detected (ng g $\left.{ }^{-1}\right)$} \\
\hline & & $\% \mathrm{RR}$ & $\% \mathrm{RSD}$ & \%RR & \%RSD & Sugar & Soil \\
\hline \multirow[t]{2}{*}{ Atrazine } & 5 & 90 & 1.0 & 111 & 0.4 & - & 0.3 \\
\hline & 50 & 103 & 5.8 & 102 & 5.8 & & \\
\hline \multirow[t]{2}{*}{ Diazinon } & 5 & 80 & 4.8 & 93 & 0.1 & - & - \\
\hline & 50 & 87 & 2.1 & 89 & 2.1 & & \\
\hline \multirow{2}{*}{ Ametryn } & 5 & 80 & 10.4 & 99 & 0.4 & - & 0.2 \\
\hline & 50 & 96 & 0.6 & 95 & 0.6 & & \\
\hline \multirow[t]{2}{*}{ Terbutryn } & 5 & 95 & 6.8 & 97 & 0.2 & - & - \\
\hline & 50 & 90 & 5.7 & 87 & 5.7 & & \\
\hline \multirow[t]{2}{*}{ Chlorpyrifos } & 5 & 79 & 0.2 & 89 & 0.1 & - & - \\
\hline & 50 & 93 & 2.3 & 97 & 2.3 & & \\
\hline \multirow[t]{2}{*}{ Dimethametryn } & 5 & 102 & 3.1 & 89 & 0.2 & - & - \\
\hline & 50 & 104 & 0.5 & 104 & 0.5 & & \\
\hline \multirow[t]{2}{*}{ 4,4'-DDE } & 5 & 89 & 6.5 & 84 & 0.4 & - & - \\
\hline & 50 & 87 & 0.8 & 88 & 0.8 & & \\
\hline \multirow{2}{*}{ 4,4'-DDD } & 5 & 100 & 0.8 & 90 & 0.6 & - & - \\
\hline & 50 & 99 & 1.8 & 102 & 1.8 & & \\
\hline \multirow[t]{2}{*}{ 4,4'-DDT } & 5 & 85 & 2.7 & 101 & 0.1 & - & - \\
\hline & 50 & 95 & 0.6 & 94 & 0.6 & & \\
\hline
\end{tabular}

Bull. Chem. Soc. Ethiop. 2021, 35(1) 

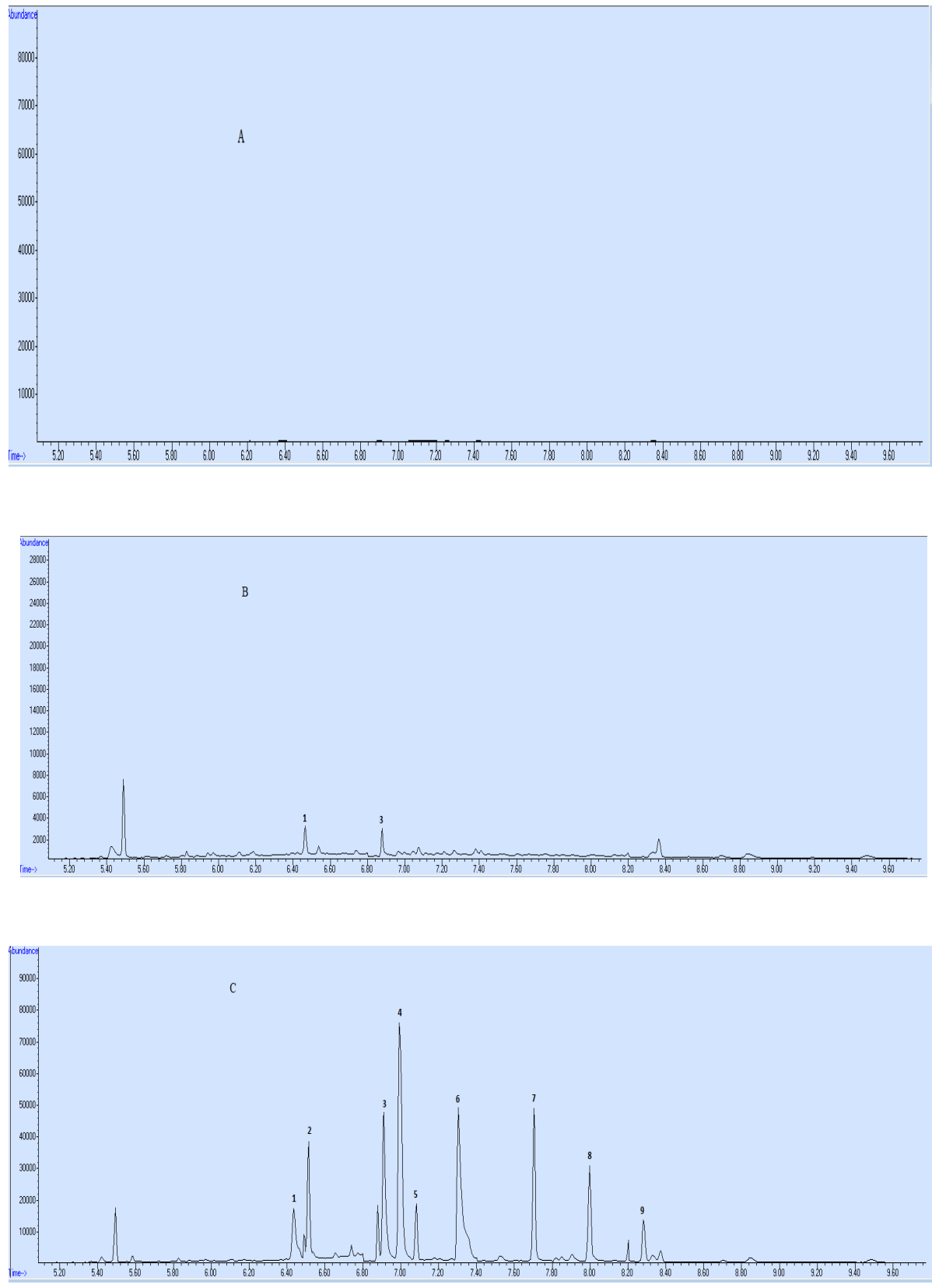

Figure 6. A representative chromatogram of blank sugar (A), soil (B) and spiked soil (C) at $5 \mathrm{ng}$ $\mathrm{g}^{-1}$. Peaks: 1, Atrazine; 2, diazinon; 3, ametryn; 4, terbutryn, 5, chloropyrifos; 6, dimethametryn; 7, 4,4'-DDE; 8, 4,4'-DDD; 9, 4,4'-DDT.

Bull. Chem. Soc. Ethiop. 2021, 35(1) 
Comparison of SALLE-LD-DLLME-GC-MS with other reported literatures

To evaluate the performances of the developed method, it was compared with the previously reported methods was carried out. This includes microwave assisted extraction coupled with gas chromatography-mass spectrometry (MAE-GC-MS) [13], dispersive liquid-liquid microextraction coupled with gas chromatography flame photometric detection (DLLME- $\mathrm{GC}-$ FPD) [23], dispersive solid-phase extraction followed by dispersive liquid-liquid microextraction combined with sweeping micellar electrokinetic chromatography (DSPEDLLME-MEKC) [45], DLLME-UV-Vis [41] and quick easy cheap effective rugged safe coupled with gas chromatography-mass spectrometry (QuEChERS-GC-MS) [46]. The merit of the methods and that of this study are given in Table 4. The performances of the developed technique were compared with that of the previously reported techniques in terms of relative recovery, LOD and correlation coefficient $\left(\mathrm{R}^{2}\right)$. Based on the findings, the developed technique was found to be comparable or better in its performance for trace level determination of the analytes under study.

Table 4. Comparison of the proposed SALLE-LD-DLLME method with related reported techniques.

\begin{tabular}{|l|l|l|c|c|c|c|c|}
\hline Method & Pesticides & Matrix & RR (\%) & $\begin{array}{c}\text { LODs } \\
\left(\mathrm{ng} \mathrm{g}^{-1}\right)\end{array}$ & \%RSD & $\mathrm{R}^{2}$ & Reference \\
\hline MAE-GC-MS & $\begin{array}{l}\text { Organophosphorus and } \\
\text { fungicides }\end{array}$ & Soil & $70-120$ & $0.1-0.12$ & $0.2-14$ & $0.992-0.997$ & {$[13]$} \\
\hline $\begin{array}{l}\text { DLLME-GC- } \\
\text { FPD }\end{array}$ & Organophosphorus & Soil & $87.4-108$ & $0.2-0.5$ & $2.0-6.6$ & $0.9987-0.9997$ & {$[23]$} \\
\hline $\begin{array}{l}\text { DSPE-DLLME- } \\
\text { MEKC }\end{array}$ & Sulfonylurea & Soil & $76.0-93.5$ & $0.3-0.8$ & $3.3-7.6$ & $0.9965-0.9983$ & {$[45]$} \\
\hline DLLME-UV-Vis & $\begin{array}{l}\text { Neonicotinoid and } \\
\text { s-triazine }\end{array}$ & $\begin{array}{l}\text { Soil and } \\
\text { water }\end{array}$ & $80.59-98$ & $0.05-0.1$ & - & $0.9924-0.9981$ & {$[41]$} \\
\hline $\begin{array}{l}\text { QuEChERS- } \\
\text { GC-MS }\end{array}$ & $\begin{array}{l}\text { Organochlorine, } \\
\text { organophosphate and } \\
\text { pyrethroid }\end{array}$ & $\begin{array}{l}\text { Wheat } \\
\text { grains, } \\
\text { flour and } \\
\text { bran }\end{array}$ & $70-120$ & 2.5 & $0.1-15.5$ & $0.9896-1.00$ & {$[46]$} \\
\hline $\begin{array}{l}\text { SALLE-LD- } \\
\text { DLLME-GC-MS }\end{array}$ & $\begin{array}{l}\text { Organochlorine, } \\
\text { organophosphate and } \\
s \text {-triazine }\end{array}$ & $\begin{array}{l}\text { Sugar } \\
\text { and soil }\end{array}$ & $79-111$ & $0.01-0.30$ & $0.1-10.4$ & $0.992-0.999$ & This study \\
\hline
\end{tabular}

\section{CONCLUSION}

This study has focused on the development of SALLE combined with LD-DLLME for selective and quantitative extraction of trace quantities of multiclass pesticide residues from complex matrices. During method development various parameters affecting the chromatographic separation and extraction efficiencies of the target analytes were evaluated and the optimum conditions were established. The enrichment factor obtained after combining SALLE to LDDLLME was in the range 30-121. The method provides very good analyte recovery (79-111\%), correlation coefficient (0.992-0.999), and LODs (0.01-0.3 $\left.\mathrm{ng} \mathrm{g}^{-1}\right)$. The current method was successfully applied for the determination of the target analytes in sugar and soil samples. The results indicated that none of the target analytes were detected in sugar while the soil sample is contaminated by atrazine and ametryn at concentration levels of 0.3 and $0.2 \mathrm{ng} \mathrm{g}^{-1}$, respectively. The experimental findings revealed that the developed method is fairly simple, cheap, rapid and reliable for selective and quantitative extraction of trace level multiclass pesticide residues from contaminated sugar and soil matrices. 


\section{ACKNOWLEDGMENTS}

Authors acknowledge the financial support from International Science Program (ISP); through ETH:04 project and the continuing assistance of the Department of Chemistry of the Addis Ababa University (AAU), for the laboratory facilities and consumables provided. Kefyalew Gomoro is grateful to Wollega University for sponsoring his $\mathrm{PhD}$ study at Addis Ababa University.

\section{REFERENCES}

1. Nguyen, T.D.; Yu, J.E.; Lee, D.M.; Lee, G. A multiresidue method for the determination of 107 pesticides in cabbage and radish using QuEChERS sample preparation methodand gas chromatography mass spectrometry. Food Chem. 2008, 110, 207-213.

2. Park, J.Y.; Choi, J.H.; El-Aty, A.A.; Kim, B.M.; Oh, J.H.; Do, J.A.; Shim, J.H. Simultaneous multiresidue analysis of 41 pesticide residues in cooked foodstuff using QuEChERS: Comparison with classical method. Food Chem. 2011, 128, 241-253.

3. Barriada-Pereira, M.; González-Castro, M.J.; Muniategui-Lorenzo, S.; López-Mahía, P.; Prada-Rodríguez, D. Organochlorine pesticides accumulation and degradation products in vegetation samples of a contaminated area in Galicia (NW Spain). Chemosphere 2005, 58, 1571-1578.

4. Huskova, R.; Matisova, E.; Kirchner, M. Fast GC-MS pesticide multiresidue analysis of apples. Chromatographia 2008, 68, 49-55.

5. Tolcha,T; Megersa, N. High density solvent based dispersive liquid-liquid micro extraction technique for simultaneous and selective extraction of multiclass pesticide residues in water and sugarcane juice samples. Am. J. Anal. Chem. 2018, 9, 224-244.

6. Salvador, I.M.; Frenich, A.G.; Gonzalez, F.J.E.; Vidal, J.L.M. Determination of organophosphorus pesticides in vegetables by GC with pulsed flame-photometric detection, and confirmation by MS. Chromatographia 2006, 64, 667-672.

7. van Leeuwen, S.P.J.; de Boer, J. Advances in the gas chromatographic determination of persistent organic pollutants in the aquatic environment. J. Chromatogr. A 2008, 1186, 161182.

8. Liu, J.; Jianga, M.; Li, G.; Xua, L.; Xie, M. Miniaturized salting-out liquid-liquid extraction of sulfonamides from differentmatrices. Anal. Chim. Acta 2010, 679, 74-80.

9. Lin, X.; Chen, X.; Huo, X.; Yu, Z.; Bi, K.; Li, Q. Dispersive liquid-liquid microextraction coupled with high-performance liquid chromatography-diode array detection for the determination of N-methyl carbamate pesticides in vegetables. J. Sep. Sci. 2011, 34, 202209.

10. Wang, W.L.; Meng, B.; Lu, X.; Liu, Y.; Tao, S. Extraction of polycyclic aromatic hydrocarbons and organochlorine pesticides from soils: A comparison between Soxhlet extraction, microwave-assisted extraction and accelerated solvent extraction techniques. Anal. Chim. Acta 2007, 602, 211-222.

11. Huo, F.; Tang, H.; Wu, X.; Chen, D.; Zhao, T.; Liu, P.; Li, L. Utilizing a novel sorbent in the solid phase extraction for simultaneous determination of 15 pesticide residues in green tea by GC/MS. J. Chromatogr. B 2016, 1023-1024, 44-54.

12. Zhao, F.; She, Y.; Zhang, C.; Cao, X.; Wang, S.; Zheng, L.; Jin, M.; Shao, H.; Jin, F.; Wang, J. Selective solid-phase extraction based on molecularly imprinted technology for the simultaneous determination of 20 triazole pesticides in cucumber samples using highperformance liquid chromatography-tandem mass spectrometry. J. Chromatogr. B 2017, 1064, 143-150.

13. Merdassa, Y.; Liu, J.; Megersa, N. Development of a one-step microwave-assisted extraction method for simultaneous determination of organophosphorus pesticides and fungicides in soils by gas chromatography-mass spectrometry. Talanta 2013, 114, 227-234.

Bull. Chem. Soc. Ethiop. 2021, 35(1) 
14. Rasmussen, K.E.; Pederson-Bjergaard, S. Developments in hollow fiber-based, liquid-phase microextraction. Trends Anal. Chem. 2004, 23, 1-10.

15. Hrouzková, S.; Brĭsová, M.; Szarka, A. Development of fast, efficient and ecological method employing vortex-assisted dispersive liquid-liquid microextraction combined with fast gas chromatography-mass spectrometry for pesticide residues analysis in alcoholcontent samples. J. Chromatogr. A 2017, 1506, 18-26.

16. Amvrazi, E.G.; Tsiropoulos, N.G. Application of single-drop microextraction coupled with gas chromatography for the determination of multiclass pesticides in vegetables with nitrogen phosphorus and electron capture detection. J. Chromatogr. A 2009, 1216, 27892797.

17. Sharifi, V.; Abbasi, A; Nosrati, A. Application of hollow fiber liquid phase microextraction and dispersive liquid-liquid microextraction techniques in analytical toxicology. J. Food Drug Anal. 2016, 24, 264-276.

18. Wang, Y.; Miao, X.; Wei, H.; Liu, D.; Xia, G.; Yang, X. Dispersive liquid-liquid microextraction combined with gas chromatography-mass spectrometry for the determination of multiple pesticides in celery. Food Anal. Methods 2016, 9, 2133-2141.

19. Merkle, S.; Kleeberg, K.K.; Fritsche, J. Recent developments and applications of solid phase microextraction (SPME) in food and environmental analysis. Chromatogr. 2015, 2, 293381.

20. Bedassa, T.; Gure, A.; Megersa, N. Low density solvent based dispersive liquid-liquid microextraction and preconcentration of multiresidue pesticides in environmental waters for liquid chromatographic analysis. J. Anal. Chem. 2015, 70, 1199-1206.

21. Matsadiq, G.; Hua, H.; Ren, H.; Zhoua, Y.; Liu, L.; Cheng, J. Quantification of multiresidue levels in peach juices, pulps and peels using dispersive liquid-liquid microextraction based on floating organic droplet coupled with gas chromatography-electron capture detection. J. Chromatogr. B 2011, 879, 2113-2118.

22. Çabuk, H.; Köktürk, M. Low density solvent-based dispersive liquid-liquid microextraction for the determination of synthetic antioxidants in beverages by high-performance liquid chromatography. Sci. World J. 2013, 2013, 1-8.

23. Yang, Z.; Liu, Y.; Liu, D.; Zhou, Z. Determination of organophosphorus pesticides in soil by dispersive liquid-liquid microextraction and gas chromatography. J. Chromatogr. Sci. 2012, 50, 15-20.

24. Tolcha, T.; Merdassa, Y.; Megersa, N. Low-density extraction solvent based solventterminated dispersive liquid-liquid microextraction for quantitative determination of ionizable pesticides in environmental waters. J. Sep. Sci. 2013, 36, 1119-1127.

25. Rezaee, M.; Assadi, Y.; Hosseini, M.R.M.; Aghaee, E.; Ahmadi, F.; Berijani, S. Determination of organic compounds in water using dispersive liquid-liquid microextraction. J. Chromatogr. A 2006, 1116, 1-9.

26. Tseng, W.C.; Chen, P.S.; Huang, S.D. Optimization of two different dispersive liquid-liquid microextraction methods followed by gas chromatography-mass spectrometry determination for polycyclic aromatic hydrocarbons (PAHs) analysis in water. Talanta 2014, 120, 425432.

27. Yan, H.; Wang, H. Recent development and applications of dispersive liquid-liquid microextraction. J. Chromatogr. A 2013, 1295, 1-15.

28. Majors, R.E. Salting-out liquid-liquid extraction. $L C-G C$ North Am. 2009, 27, 526-533.

29. Xu, X.Y.; Ye, J.Q.; Nie, J.; Li, Z.G.; Lee, M.R. A new liquid-liquid microextraction method by ultrasound assisted salting-out for determination of triazole pesticides in water samples coupled by gas chromatography-mass spectrometry. Anal. Methods 2015, 7, 1194-1199.

30. Singh, M.; Singh, S; Asiri, A.M. IFT and friccohesity study of formulation, wetting, dewetting of liquid systems using oscosurvismeter. J. Mol. Liq. 2017, 244, 7-18. 
31. Alemayehu, Y.; Tolcha, T.; Megersa, N. Salting-out assisted liquid-liquid extraction combined with HPLC for quantitative extraction of trace multiclass pesticide residues from environmental waters. Am. J. Anal. Chem. 2017, 8, 433-448.

32. Gure, A.; Lara, F.J; Garcia-Campana, A.M.; Megersa, N.; Olmo-Iruela, M. Vortex-assisted ionic liquid dispersive liquid-liquid microextraction for the determination of sulfonylurea herbicides in wine samples by capillary high-performance liquid chromatography. Food Chem. 2015, 170, 348-353.

33. Niu, Z.; Yu, C.; He, X.; Zhang, J.; Wen, Y. Salting-out assisted liquid-liquid extraction combined with gas chromatography-mass spectrometry for the determination of pyrethroid insecticides in high salinity and biological samples. J. Pharm. Biomed. Anal. 2017, 143, $222-227$.

34. Gure, A.; Lara, F.J.; Garcia-Campana, A. M.; Megersa, N.; Olmo-Iruela, M. Salting-out assisted liquid-liquid extraction combined with capillary HPLC for the determination of sulfonyl urea herbicides in environmental water and banana juice samples. Talanta 2014, 127, 51-58.

35. Walorczyk, S.; Drozdzynski, D. Improvement and extension to new analytes of a multi residue method for the determination of pesticides in cereals and dry animal feed using GCtandem quadrupole MS revisited. J. Chromatogr. A 2012, 1251, 219-231.

36. Xu, X.; Ye, J.; Nie, J.; Li, Z.; Lee, M. A new liquid-liquid microextraction method by ultrasound assisted salting-out for determination of triazole pesticides in water samples coupled by gas chromatography-mass spectrometry. Anal. Methods 2015, 7, 1194-1199.

37. Hajkova, K.; Jurasek, B.; Sykora, D.; Palenicek, T.; Miksatkova, P.; Kuchar, M. Salting-outassisted liquid-liquid extraction as a suitable approach for determination of methoxetamine in large sets of tissue samples. Anal. Bioanal. Chem. 2016, 408, 1171-1181.

38. Rodríguez-Cabo, T.; Ramil, M.; Rodríguez, I.; Cela, R. Dispersive liquid-liquid microextraction with non-halogenated extractants for trihalomethanes determination in tap and swimming pool water. Talanta 2012, 99, 846-852.

39. Wen, Y.; Li, J.; Yang, F.; Zhang, W.; Li, W.; Liao, C.; Chen, L. Salting-out assisted liquidliquid extraction with the aid of experimental design for determination of benzimidazole fungicides in high salinity samples by high-performance liquid chromatography. Talanta 2013, 106, 119-126.

40. Zhang, J.; Wu, H.; Kim, E.; El-Shourbagy, T.A. Salting-out assisted liquid-liquid extraction with acetonitrile: a new high throughput sample preparation technique for good laboratory practice bioanalysis using liquid chromatography-mass spectrometry. Biomed. Chromatogr. 2009, 23, 419-425.

41. Joarder, R.; Santra, D.; Marjit, S.; Sarkar, M. Preconcentration and recovery of pesticides from soil and water by dispersive liquid-liquid extraction. Eur. Chem. Bull. 2014, 3, 612616.

42. Jouyban, A.; Sorouraddin, M.H.; Farajzadeh, M.A.; Somi, M.H.; Fazeli-Bakhtiyari, R. Determination of five antiarrhythmic drugs in human plasma by dispersive liquid-liquid microextraction and high-performance liquid chromatography. Talanta 2015, 134, 681-689.

43. Pandey, P.; Raizada, R.B.; Srivastava, L.P. Level of organochlorine pesticide residues in dry fruit nuts. J. Environ. Biol. 2010, 31, 705-707.

44. Farajzadeh, M.A.; Khoshmaram, L. Development of dispersive liquid-liquid microextraction technique using ternary solvents mixture followed by heating for the rapid and sensitive analysis of phthalate esters and di(2-ethylhexyl) adipate. J. Chromatogr. A 2015, 1379, 24-33.

45. Zhang, S.; Yin, X.; Yang, Q.; Wang, C.; Wang, Z. Determination of some sulfonylurea herbicides in soil by a novel liquid-phase microextraction combined with sweeping micellar electrokinetic chromatography. Anal. Bioanal. Chem. 2011, 401, 1071-1081. 
46. Kolberg, D.I.; Prestes, O.D.; Adaime, M.B.; Zanella, R. Development of a fast multiresidue method for the determination of pesticidesin dry samples (wheat grains, flour and bran) using QuEChERS based method and GC-MS. Food Chem. 2011, 125, 1436-1442. 